NASA Technical Memorandum 83663

\title{
Performance of Thermal Barrier Coatings in High Heat Flux Environments
}

- Robert A. Miller

Lewis Research Center

Cleveland, Ohio

and

Christopher C. Berndt

Cleveland State University

Cleveland, Ohio

Prepared for the

International Conference on Metallurgical Coatings sponsored by the American Vacuum Society

San Diego, California, April 9-13, 1984 
PERFORMANCE OF THERMAL BARRIER COATINGS IN HIGH HEAT FLUX ENVIRONHENTS

\author{
Robert A. Miller \\ National Aeronautics and Space Administration \\ Lewis Research Center \\ Cleveland, Ohio 44135
}

and

Christopher C. Berndt*

Cleveland State University

Cleveland, Ohio 44115

\begin{abstract}
SUMMARY
Thermal barrier coatings were exposed to the high temperature and high heat flux produced by a $30 \mathrm{~kW}$ plasma torch. Analys is of the specimen heating rates indicates that the temperature drop across the thickness of the $0.038 \mathrm{~cm}$ ceramic layer was about $1100^{\circ} \mathrm{C}$ after $0.5 \mathrm{sec}$ in the flame. An as-sprayed $\mathrm{ZrO}_{2}-8 \% \mathrm{Y}_{2} \mathrm{O}_{3}$ specimens survived 3000 of the $0.5 \mathrm{sec}$ cycles with failing. Surface spaling was observed when $2.5 \mathrm{sec}$ cycles were employed but this was attributed to uneven heating caused by surface roughness. This surface spalling was prevented by smoothing the surface with silicon carbide paper or by laser glazing. A coated specimen with no surface modification but which was heat treated in argon also did not surface spall. Heat treatment in air led to spalling in as early as 1 cycle from heating stresses. Failures at edges were investigated and shown to be a minor source of concern. Ceramic coatings formed from $\mathrm{ZrO}_{2}-12 \mathrm{KY}_{2} \mathrm{O}_{3}$ or $\mathrm{ZrO}_{2}-20 \% \mathrm{YY}_{2} \mathrm{O}_{3}$ were shown to be unsuited for use under the high heat flux conditions of this study.
\end{abstract}

\title{
INTRODUCTION
}

A thermal barrier coating system with sufficient durability to survive on airfoil surfaces in a moderately high heat flux, moderately high temperature." research gas turbine engine was first reported in the mid 1970's (refs. 1 and 2). However, this early thermal barrier coating system, which consisted of a layer of air plasma sprayed $\mathrm{ZrO}_{2}-12 \mathrm{\% Y}_{2} \mathrm{O}_{3}$ applied directly over a layer of air plasma sprayed NiCrAly bond coat, was unable to survive in an advanced research gas turbine engine (ref. 3). Thermal barrier coatings have now been improved to the extent that they are used in revenue service on vane platforms in advanced, commercial gas turbine engines (ref. 4). Among the more significant advances responsible for this current success is the discovery that a $\mathrm{ZrO}_{2}-8 \% \mathrm{Y}_{2} \mathrm{O}_{3}$ coating is much more durable than the earlier, $\mathrm{ZrO}_{2}-12 \% \mathrm{Y}_{2} \mathrm{O}_{3}$ version (ref. 5). Possible reasons for this are discussed in reference 6 .

In the future, advanced engines operating at heat fluxes greater than those characteristic of current engines will require thermal barrier coatings for protecting airfoil surfaces. The testing which has led to advances in

*Fellow of the Joint Institute for Aerospace Propulsion and Power. 
coating performance has been conducted in the low to moderate heat flux environment of furnaces and burner rigs. The initiation of coating failure in such rigs is associated with thermal expansion mismatch strain encountered on cooling and with time-at-temperature effects such as bond coat oxidation and plastic deformation (ref. 7). Strains encountered on heating in such rigs are not severe enough to initiate coating failure (ref. 7 ). It is not yet known whether strains encountered on heating in a gas turbine engine are severe enough to contribute to failure initiation.

Therefore, testing procedures must be devised that allow determination of when the thermal loads developed on rapid heating become severe enough to initiate coating failure. This information may then be used to guide the processing of coatings for improved tolerance to such loads. In this study, a commercial plasma torch has been used as a high heat flux source. Various plasma sprayed zirconia-yttria thermal barrier coating systems were exposed in this rig and the response of these coatings to the high heat flux environment generated was characterized.

The plasma torch rig used for this study is intended to serve as an interim rig until a high pressure burner rig and a rocket engine test rig dedicated to materials research are available at the Lewis Research Center. Precedents for this type of test exist (refs. 8 and 9). The torch is relatively simple and inexpensive to operate. Possible disadvantages of this rig include the small flame diameter and the extremely high gas temperature attained.

\section{EXPERIMENTAL}

A schematic diagram of the test rig is shown in figure 1 . The plasma torch shown is operated at a power level of $30 \mathrm{~kW}$. The nitrogen arc gas flow rate was $2800 \mathrm{l} / \mathrm{hr}$. The distance from the exit nozzle of the torch to the specimen is $4.4 \mathrm{~cm}$. Specimens are held in the flame for either $0.5,2.5$, or $5.0 \mathrm{sec}$ cycles followed by 30,75 , or $120 \mathrm{sec}$ of forced air cooling. An additional $0.50 \mathrm{sec}$ is required for the specimen to move between the cooling position and the heating position, and specimen heating begins before the specimens are fully in the heating position. Therefore effective heating times may be taken as $0.1 \mathrm{sec}$ longer than the nominal times.

Test specimens were solid $1.3 \mathrm{~cm}$ diameter superalloy rods. Usually the alloy was René 41 . The thermal barrier coatings consisted of $0.013 \mathrm{~cm}$ of bond coat which was usually $\mathrm{Ni}-14 \% \mathrm{Cr}-14 \% \mathrm{Al}-0.1 \mathrm{Zr}$ under a $0.038 \mathrm{~cm}$ layer of plasma sprayed zirconia-yttria ceramic. The yttria level was usually 8 wt $\% ; 12$ and 20 wt $\%$ yttria ceramics were also investigated. Sintered starting powders were used for the 8 and $12 \%$ yttria compositions while a nonreacted composite powder was used for the $20 \%$ yttria composition.

Specimens were tested in the as-sprayed condition, after heat treating in air or in argon, and after surface treatment by smoothing with silicon carbide paper or laser glazing. The laser glazed specimens were only available as hollow, cylindrical specimens. 


\section{RESULTS AND DISCUSSION}

\section{Characterization of the Plasma Flame and of Specimen Heating Rates}

The apparent gas temperature of a $30 \mathrm{~kW}$ nitrogen plasma at a distance of $4.4 \mathrm{~cm}$ from the nozzle was determined through measurement of the power required to melt small samples of $\mathrm{Al}_{2} \mathrm{O}_{3}$ or $\mathrm{ZrO}_{2}-6 \mathrm{KY}_{2} \mathrm{O}_{3}$. A plot of the logarithm of the known melting (or solidus) points versus the logarithm of the power required to me it the samples gives a line of slope equal to $1 / 4$ as shown in figure 2 . This slope arises from the Stefan-Blotzman relationship and is consistent with the assumption that heat is transferred from the cathode of the plasma torch to the plasma by radiation (ref. 10) and from the gas to the samples by convection and conduction (ref. 11).

Extrapolation of the line in figure 2 to $30 \mathrm{~kW}$ yields an apparent flame temperature of $3000^{\circ} \mathrm{C}$. The actual gas temperature may differ somewhat since heat will be lost from the sample by radiation or gained by aerodynamic heating.

The heat transfer coefficient from the gas to the sample was measured to be $0.2 \mathrm{~W} \mathrm{~cm}^{-2}{ }^{\circ} \mathrm{C}^{-1}$. A button calorimeter similar to the ones described in references 9 and 12 but of simplified design was used for this determination. The heat transfer coefficient and the apparent gas temperature were used to calculate the temperature distributions in the coated specimens as a function of time. A one-dimensional finite difference model was used for this calculation. The computer code employed was taken from reference 13 (the reader is cautioned that there are several errors in the FORTRAN listing given in ref. 13). Values for the thermal conductivities and heat capacities of the bond coat and ceramic were taken from reference 14 . Values pertaining to $500^{\circ} \mathrm{C}$ were used.

The calculated heating rates at the ceramic surface and at the interface with the bond coat are presented in figure 3 . An initial response of $0.1 \mathrm{sec}$ was assumed as explained in the experimental section. Temperatures measured by a thermocouple centered $0.076 \mathrm{~cm}$ below the interface are also shown on the plot. These temperatures appear to be consistent with the calculated interface temperatures. The time at which the surface of the specimen was observed to be fully glowing in a $1 / 8000 \mathrm{sec}$ photograph is also indicated on the plot. This time corresponds to a calculated surface temperature of about $1100^{\circ} \mathrm{C}$, and the observation of glowing at this temperature seem plausible in view of the very short exposure time.

A very large $\Delta T$ between the surface and the interface has been achieved in this test. At $0.5 \mathrm{sec}$ this difference is almost $1100^{\circ} \mathrm{C}$. As shown in the figure this is much greater than the $\Delta T$ calculated for a $0.018 \mathrm{~cm}$ ceramic coating in a research gas turbine engine during the take-off portion of the cycle (ref. 3 ) and is greater still than the $\Delta T$ for a $0.038 \mathrm{~cm}$ coating in a Mach 0:3 burner rig (ref. 15).

One can calculate the compressive thermal strain at the surface of the ceramic relative to the mean thermai strain in the ceramic from the expression (ref. 16)

$$
\varepsilon=a\left(\overline{\mathrm{T}}-\mathrm{T}_{\text {surf }}\right)
$$


where $\alpha$ is the thermal expansion coefficient of the ceramic -- about $10 \times 10^{-6}$ (ref. 17) -- and $\overline{\mathrm{T}}$ is the mean temperature in the ceramic layer. The values of the relative strain calculated from expression 3 are $-0.57,-0.48$, and $-0.42 \%$ at $0.5,2.5$, and $5.0 \mathrm{sec}$, respectively. One may note that surface compressive strains are larger after $0.5 \mathrm{sec}$ than after $2.5 \mathrm{or} 5.0 \mathrm{sec}$. A complete calculation of strain would include ceramic/metal thermal expansion mismatch strains and residual stress.

From the above analysis it is apparent that the thermal loads imposed on coated specimens in this plasma torch rig are much more severe than those to be expected in a gas turbine engine.

\section{Response of Thermal Barrier Coating to High Heat Flux}

The results of this investigation are displayed in figure 4 . In this figure the composition of the ceramic, the pretreatment given to the specimen, the duration of the heat cycle, and the type of failure observed, if any, are given. The total number of cycles is represented by the length of the bar. A pointed arrow indicates no failure. The test was terminated if no failure was observed after $10000.5 \mathrm{sec}$ cycles or after $1002.5 \mathrm{sec}$ cycles. An exception was case $A$ which ran for 3000 cycles before removing from the test.

Case $A$ pertains to as-sprayed $\mathrm{ZrO}_{2}-8 \% \mathrm{Y}_{2} \mathrm{O}_{3}$ ceramic and the lack of failure after 3000 cycles is quite encouraging. When the cycle duration was increased to 2.5 or $5.0 \mathrm{sec}$, cases $B$ and $C$, respectively, then surface spalling was observed after 15 cycles: This surface spalling was observed even though the relative surface strains at the end of the $2.5 \mathrm{sec}$ cycles exceeded those at the end of the $0.5 \mathrm{sec}$ cycles. A photograph of the surface of the specimen from case $B$ is shown in figure 5 . In case $C$ the surface spalling was accompanied by surface melting even though the calculated temperature after 5 sec (fig. 3) was about $800^{\circ} \mathrm{C}$ lower than the melting point of the ceramic. This indicates that there must be local hot spots on the rough surface. High speed photography indicated that some regions of the rough specimen began to glow almost $0.1 \mathrm{sec}$ before the surface came to a full glow. This local glowing occurs even before the specimen comes fully into position. Therefore one can. expect that there will be areas of severe local stress concentration at the rough surface of a specimen exposed to these very high temperatures.

Smoothing the coating surface with silicon carbide paper, case $D$ and figure 6 , prevents surface spalling. This smoothing reduced the measured roughness from about $10 \mu(A A)$ to about $4 \mu(A A)$. A laser glazed specimen did not surface spall after $152.5 \mathrm{sec}$ cycles, case $F$. The results for the laser glazed specimen must be considered preliminary because the only specimens available at the time of this study were on hollow substrates which had previously been tested to failure in the hot zone region in a burner rig test. Regions away from the failure area were exposed in the plasma torch rig. The specimen in case $F$ actually spalled after 20 cycles. However, at the present time it is not known whether this may have been due to some factor such as overheating of the hollow specimen. The laser glazed specimen in case $E$ survived $10000.5 \mathrm{sec}$ cycles but it cracked and eventually spalled in the unglazed region near the upper edge as shown in figure 7 . It should be noted that the cracks emanating from the unglazed areas dissipate once they reach the mudcracked, laser glazed region. Thus, even though the results on laser glazed 
specimens are preliminary, this process (which is discussed in ref. 18) is promising for high heat flux applications.

Since spalling had been observed at the edge of the hollow specimen in case $E$, the response of a solid specimen to heating at an edge was investigated. No edge effect spalling was observed after $10000.5 \mathrm{sec}$ cycles, case G. However, a minor amount of edge spalling was observed after 3 of the $2.5 \mathrm{sec}$ cycles, case $H$ and figure 8 .

Case I indicates that there is a strong correlation between oxidation and spalling on heating. A specimen which had received a relatively severe oxidative heat treatment -- $20 \mathrm{hr}$ at $1200^{\circ} \mathrm{C}$ in air -- spalled in the first cycle in one test (fig. 9) and in the third cycle in another test. Presumably the ceramic had been weakened near the interface with the bond coat as a result of strains induced by the formation of an oxide layer at the interface combined with thermal expansion mismatch strains encountered on cooling. A specimen heated for $20 \mathrm{hr}$ at $1250^{\circ} \mathrm{C}$ in an inert environment, case $\mathrm{J}$ and fig. 10 , did not spall and did not even surface spall after $1002.5 \mathrm{sec}$ cycles.

A $\mathrm{ZrO}_{2}-12 \% \mathrm{Y}_{2} \mathrm{O}_{3}$ coated specimen was severely microcracked after $2500.5 \mathrm{sec}$ cycles, case $K$. This specimen was subsequently destroyed when it became stuck in the heating position. Another $\mathrm{ZrO}_{2}-12 \% \mathrm{Y}_{2} \mathrm{O}_{3}$ specimen began to spall after $72.5 \mathrm{sec}$ cycles, case L. Three $\mathrm{ZrO}_{2}-20 \% \mathrm{Y}_{2} \mathrm{O}_{3}$ specimens, case $\mathrm{M}$, spalled during the first cycle.

\section{CONCLUDING REMARKS}

The above results show that thermal barrier coatings having a ceramic layer based on $\mathrm{ZrO}_{2}-8 \% \mathrm{Y}_{2} \mathrm{O}_{3}$ can withstand thermal strains greatly in excess of those expected in a gas turbine engine. Surface spalling associated with extremely high gas temperatures was encountered but this could be prevented by smoothing the surface with silicon carbide paper. Heat treating in an inert environment may also prevent surface spalling. Results on laser glazed specimens are preliminary, but it appears that glazed specimens also withstand heating stresses quite well.

Oxidation appears to induce spalling on heating. Thus oxidation has been implicated as a key factor in coating failure in both the heating mode in high heat flux plasma torch tests and in the cooling mode in moderate heat flux burner rig tests. This observation is callse for concern regarding the use of coatings for long periods of time in a high heat flux environment. Therefore, the effects of oxidation require further investigation. Spalling at an edge may be a minor concern. Coatings formed from $\mathrm{ZrO}_{2}-12 \%_{2} \mathrm{O}_{3}$ or $\mathrm{ZrO}_{2}-20 \mathrm{KY}_{2} \mathrm{O}_{3}$ were unsuited for use at the high heat flux generated by the plasma torch.

\section{REFERENCES}

1. S. Stecura, "Two-Layer Thermal Barrier Coating for Turbine Airfoils Furnace and Burner Rig Test Results, "NASA TM-X-3425, Sept. 1976.

2. C. H. Liebert, R. E. Jacobs, S. Stecura and C. R. Morse, "Durability of Zirconia Thermal-Barrier Ceramic Coatings on Air-Cooled Turbine Blades in Cyclic Jet Engine Operation," NASA TM-X-3410, Sept. 1976. 
3. W. R. Sevcik and B. L. Stoner, PWA-5590 (Pratt and Whitney Aircraft Group, East Hartford, CT, 1978) NASA CR-135360.

4. K. D. Sevcik and B. L. Stoner, PWA-5590 (Pratt and Whitney Aircraft Group, East Hartford, CT, 1982) NASA CR-167964.

5. S. Stecura, "Effects of Compositional Changes on the Performance of a Thermal Barrier Coating System - Yttria-Stabilized Zirconia Coatings on Gas Turbine Engine Blades," NASA TH-78976.

6. R. A. Miller, R. 6. Garlick and J. L. Smialek, Am. Ceram. Soc. Bull. 62, 1355-1358, (1983),

7. R. A. Miller and C. E. Lowell, Thin Solid Films, 95, 265-273, (1982).

8. A. N. Current, S. J. Grisaffe and K. C. Wycoff, "Hydrogen Plasma Tests of Some Insulating Coating Systems for the Nuclear Rocket Thrust Chamber," (1982).

9. H. E. Smith and J, C. Wurst, "The Evaluaton of High Temperature Materiais Systems with an Arc-Plasma-Jet," ASD-TDR-623-655, July 1962.

10. C. W. Chang and J. Szekely, J. Metals, 34, no. 2, 57-64, (1982).

11. M. Ushio, J. Szekely, and C. W. Chang, Ironmaking Steelmaking, 8 , 279-286, (1981).

12. J. Huminik, High-Temperature Inorganic Coatings (Reinhold, New York, 1963, 197-198.)

13. H. Schenck, FORTRAN Methods in Heat Flow (Ronald Press, New York, 1963, pp. 93-106.)

14. P. A. Siemers and W. B. Hillig, SRD-81-083 (General Electric Co., St. Petersburg, FL, 1981) NASA CR-165351.

15. G. McDonald and R. C. Hendricks, Thin Solid Films, 73, 491-496, (1980).

16. S. S. Manson, Thermal Stress and Low-Cycle Fatique, (McGraw-Hill, New York, 1966, p. 277.)

17. C. C. Berndt and H. Herman, Ceram. Eng. Sci. Proc., 4, 792-801, (1983).

18. I. Zaplatynsky; Thin Solid Films, 95, 275-284, (1982). 


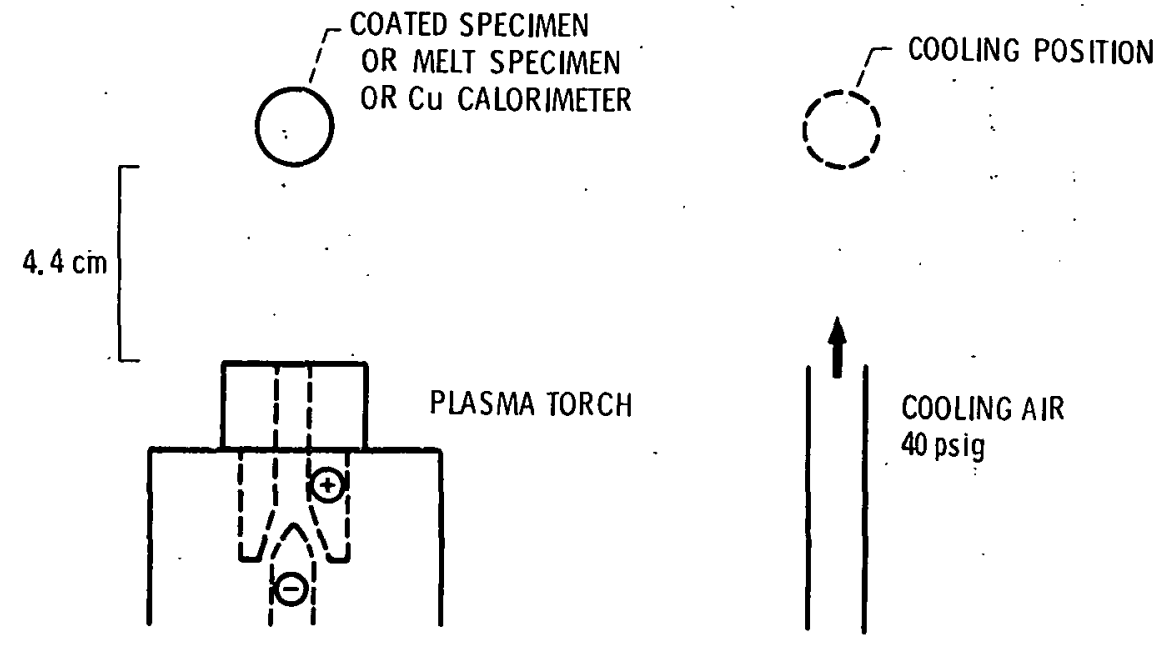

Figure 1. - Schematic diagram of plasma torch test rig.

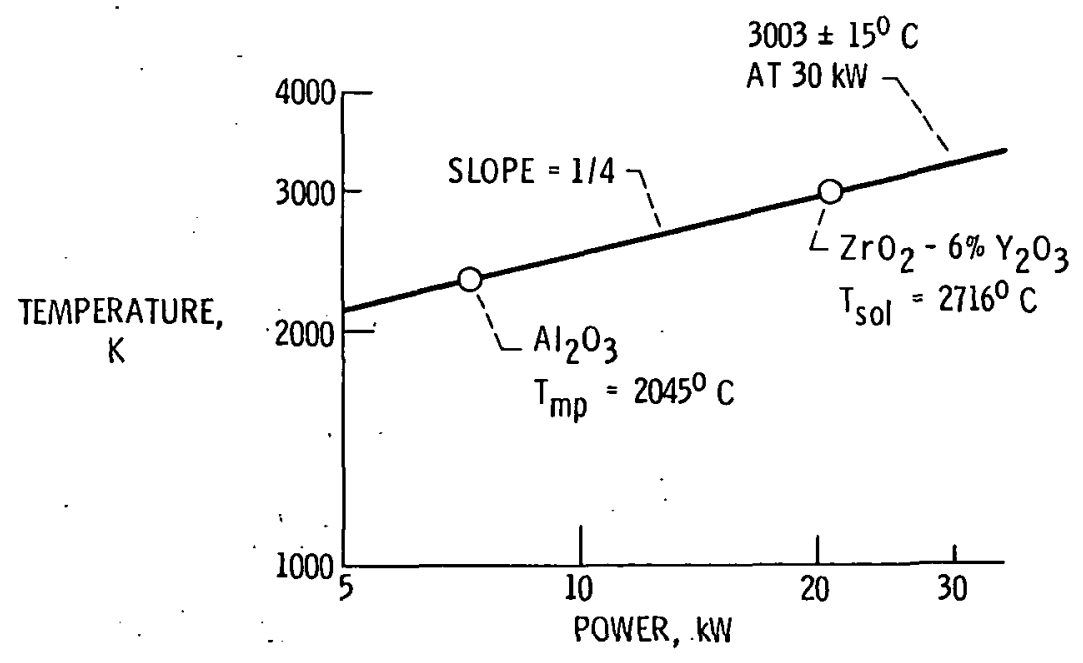

Figure 2. - Plasma torch arc power versus apparent gas temperature. 

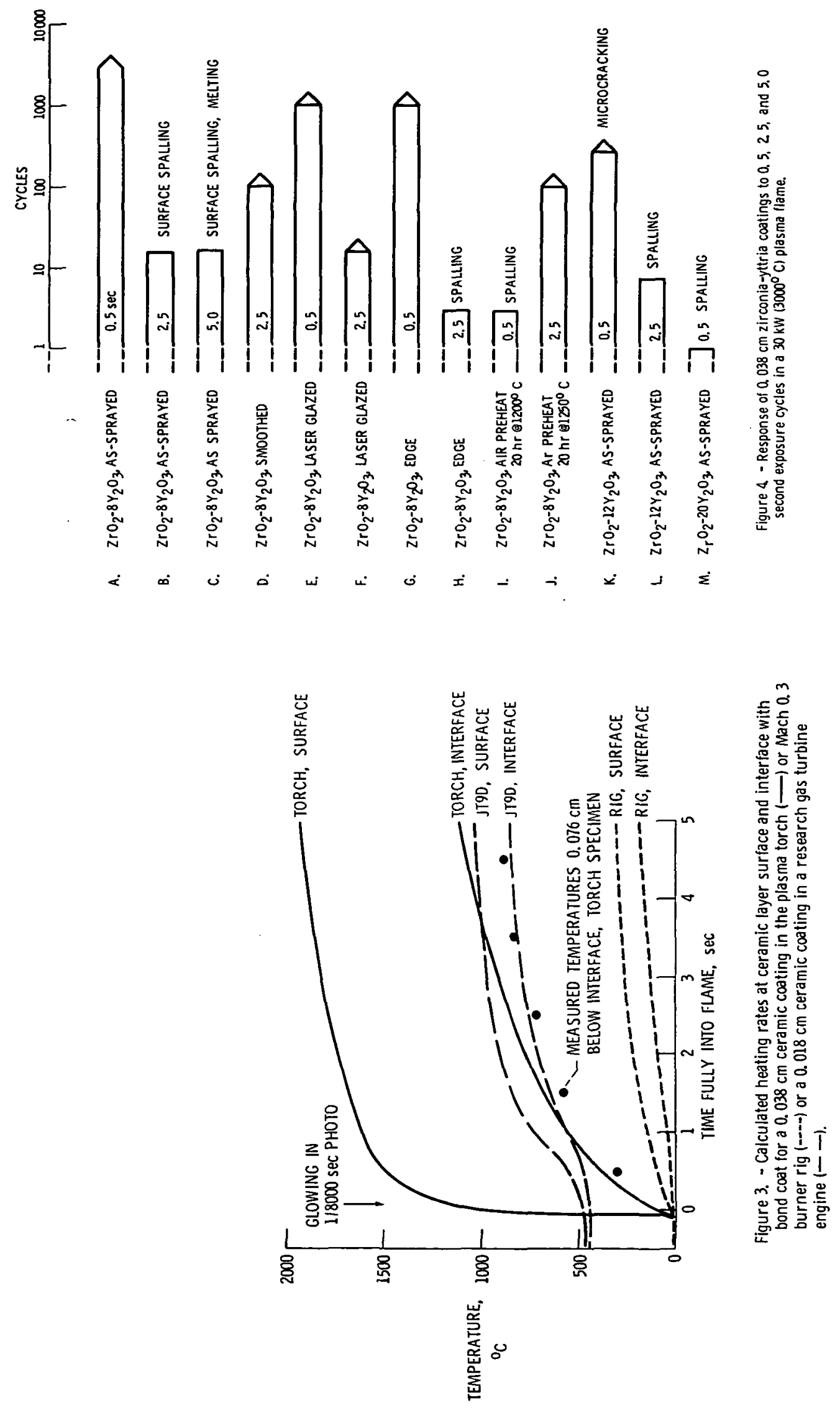

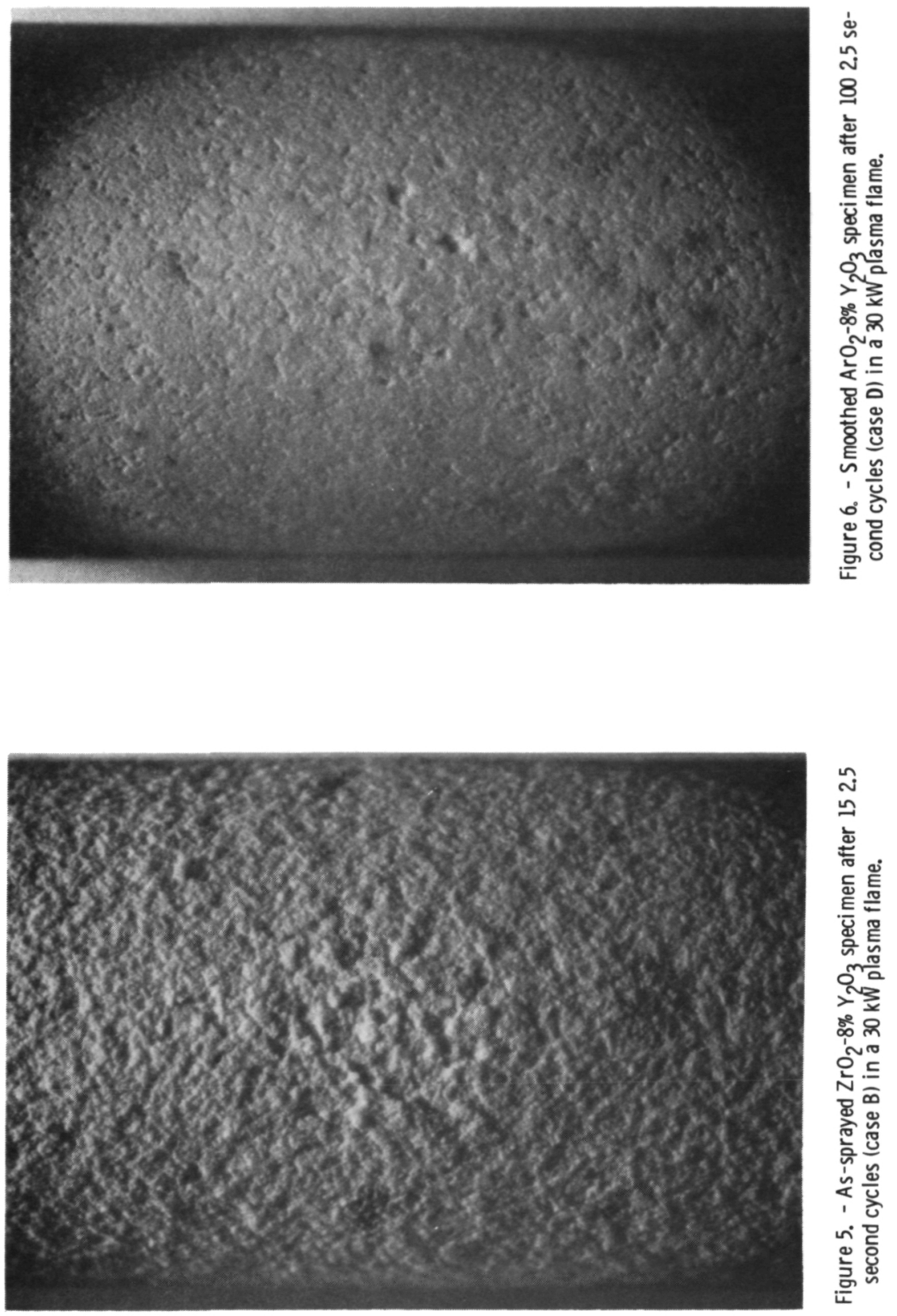

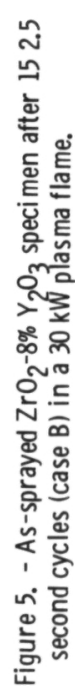



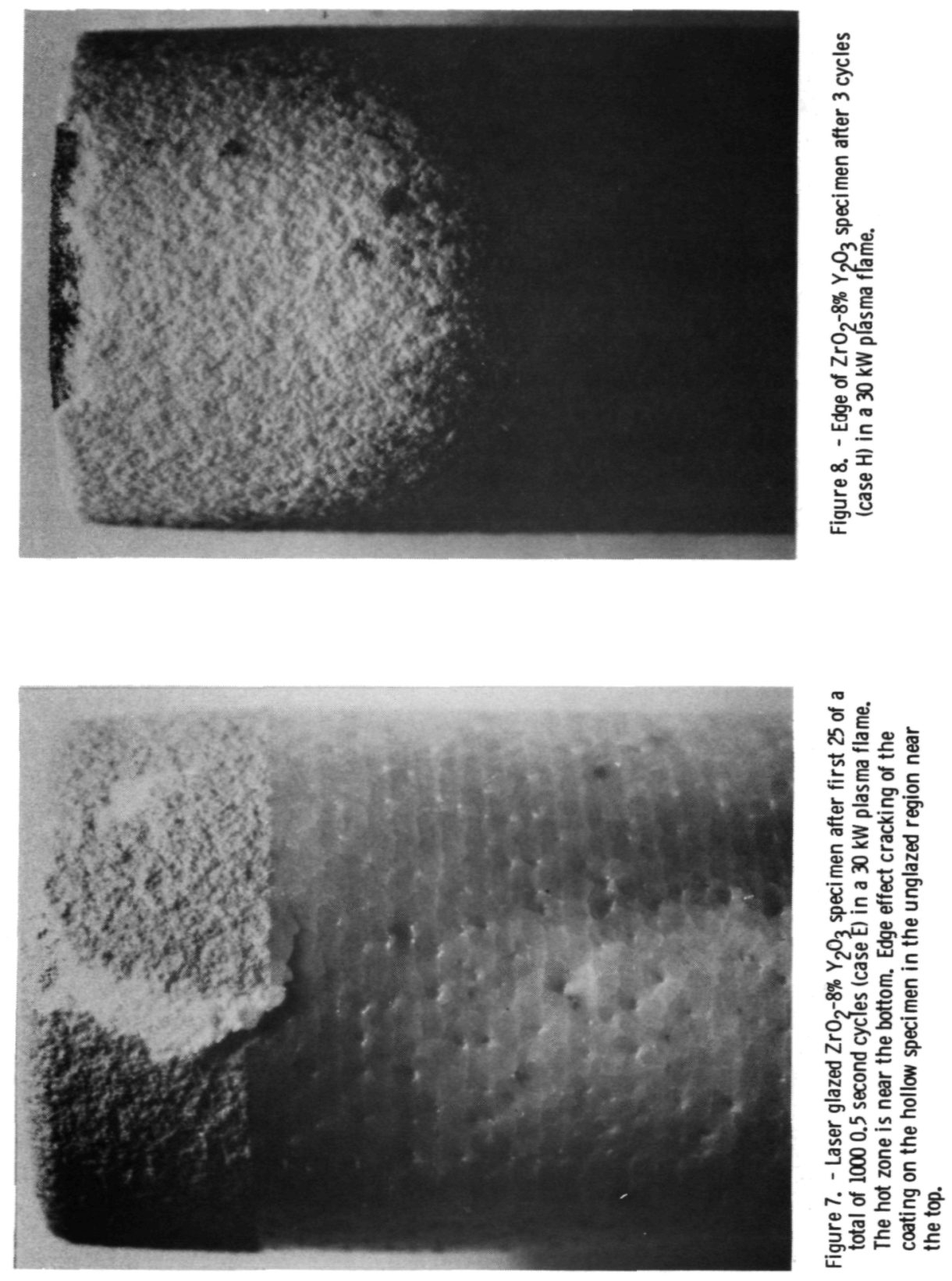


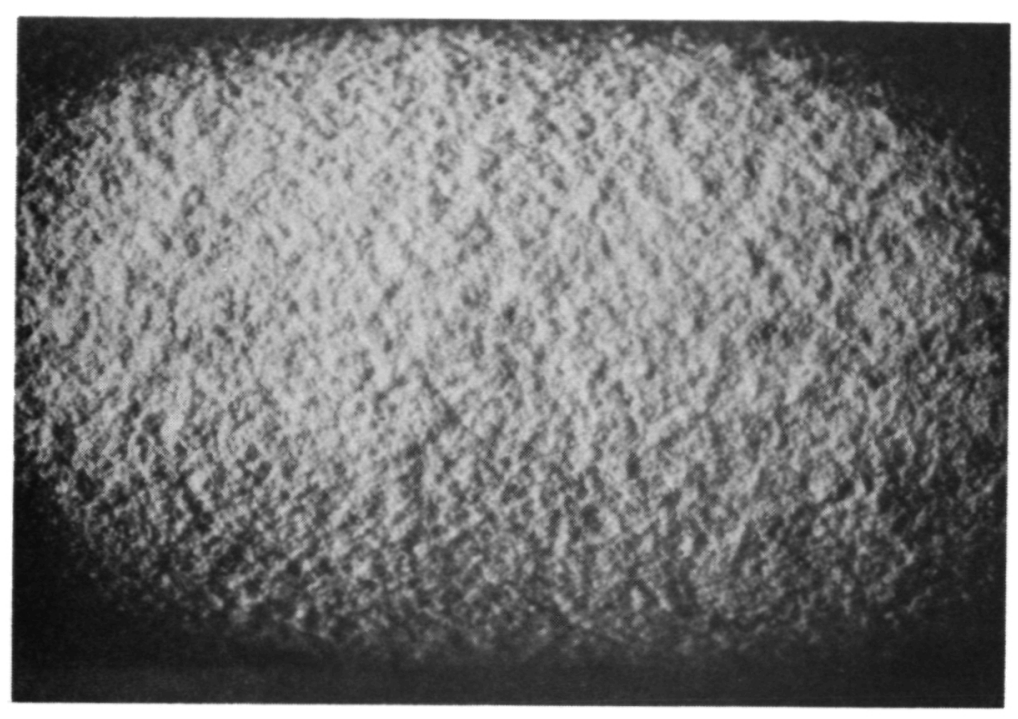

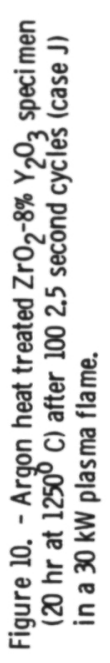

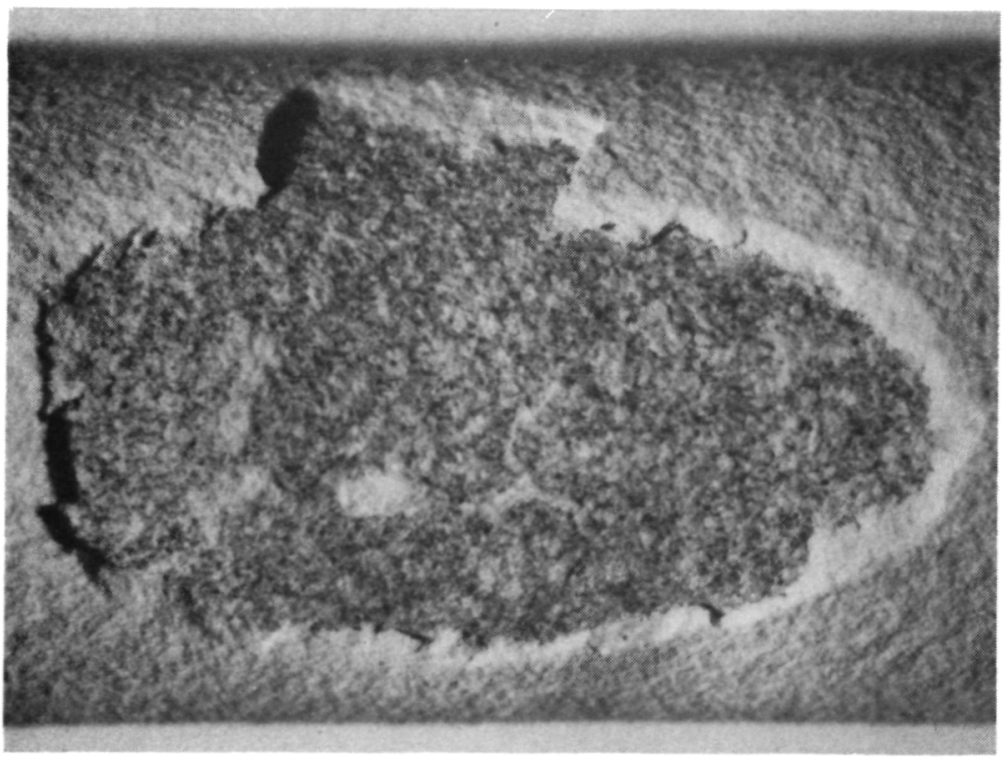

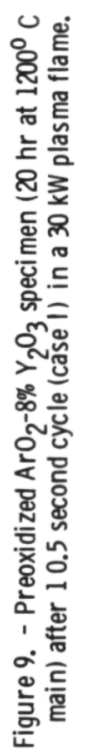







National Aeronautics and Space Administration

Washington, D.C.

20546

Otficial Business

Penalty for Privene Use, $\mathbf{5 3 0 0}$
SAECIAL FOURTH CLASS MAIL BOOK

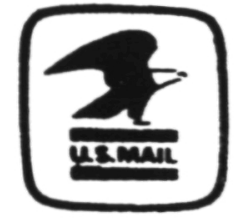

Postage and Fees Paid Netional Aeroneutics and Spece Administration NASA -451 